\title{
Incorporação nominal em línguas ergativo-absolutivas
}

\section{Dirceu Fernandes Lira de Sena (PG)}

\section{Resumo}

O objetivo do projeto foi analisar os casos de incorporação nominal (IN) em línguas ergativo-absolutivas, com enfoque nos casos de IN de sujeito. Para tanto, foi proposto que, na primeira etapa da pesquisa, fossem reunidos, em um banco de dados, exemplos de tipos de IN em línguas ergativo-absolutivas. $\mathrm{Na}$ segunda etapa, buscou-se encontrar padrões nos casos de IN de sujeito, com base no corpus formado, e encontrar alguma relação entre esses casos e o alinhamento morfossintático dessas línguas.

Palavras Chave: tipologia; línguas indígenas; incorporação nominal.

\section{Introdução}

O objetivo deste projeto foi analisar os casos de incorporação nominal (IN) em línguas ergativo-absolutivas, com especial atenção para os casos de IN de sujeito.

Para levar a cabo esta pesquisa, foi proposto que, nos primeiros seis meses de desenvolvimento do projeto, fossem reunidos em um único banco de dados exemplos de todos os tipos de IN (segundo tipologia proposta por Mithun, 1984) em línguas ergativo-absolutivas. Na segunda etapa da pesquisa, o objetivo seria tentar encontrar algum padrão nos casos de IN de sujeito, com base no corpus formado, e tentar encontrar alguma relação entre os casos de IN de sujeito e o alinhamento morfossintático da língua em que estão ocorrendo esses casos de IN.

\section{Resultados e Discussão}

Os resultados parciais confirmam o que já é conhecido na literatura: de fato, quando há uma incorporação de sujeito, este funciona como sujeito de um verbo inacusativo. Além disso, o argumento externo de uma oração transitiva $(A)$ jamais é incorporado. Quanto ao alinhamento morfossintático, os resultados preliminares mostram que provavelmente não há nenhuma influência do alinhamento na probabilidade de serem atestados casos de IN.

Quando se comparam os dados de IN em línguas ergativo-absolutivas com os dados de IN em línguas de outros alinhamentos, a primeira impressão é a da que o alinhamento morfossintático da língua não é determinante na escolha do elemento incorporado. Os fatores que determinam sua escolha são: 1) fatores semânticos do próprio substantivo (alienável, nãoalienável, animado, inanimado, etc.); 2) sua função na oração (agente, paciente, locatum, instrumento, etc.); 3) contexto em que a sentença com IN está sendo dito (referencialidade ou não- referencialidade do nome, designação de atividades habituais ou não, etc.).

\section{Conclusões}

Com base nos resultados preliminares, percebe-se a necessidade de que se proceda uma pesquisa em que sejam analisados os fatores semânticos associados à IN.

Para que haja uma explicação linguística para a atestada assimetria entre os casos de IN de sujeitos em proporção aos casos de IN de objeto, faz-necessário que sejam analisados os possíveis fatores semânticos que estejam associados ou que determinem essa assimetria. Essa assimetria talvez possa ser explicada como consequência de alguma regra semântica.

\section{Agradecimentos}

Os agradecimentos vão para meu orientador, Angel Mori, pela extensa bibliografia sugerida, e para agência SAE/Unicamp pelo apoio financeiro no concedimento de uma bolsa PIBIC.

CAMPBELL, L Typological characteristics of South American indigenous languages. The Indigenous Languages of South America: a comprehensive guide. (ed.) CAMPBELL, Lyle.; GRODONA, V. Berlim: Walter de Gruyter, 2012

COMRIE, B. Language Universals and Linguistic Typology: Syntax and Morphology. 2.ed. Oxford: Basil Blackwell, 1989.

1 MITHUN, M. The evolution of noun incorporation. Language 60(4): 847- 894.Linguistic Society of America. 1984.

MITHUN, M. Ergativity and language contact on the Oregon Coast: Alsea, Siuslaw and Coos. In: SIMPSON, Andrew K. (ed.). Proceedings of the Twenty-Sixth Meeting of the Berkeley Linguistics Society, special issue on the Syntax and Semantics of the Indigenous Languages of the Americas, p.77-95. Berkeley: Berkeley Linguistics Society, 2000 .

RAMIREZ, H. Ergatividade em Yanomami. Ergatividade na Amazônia II, Atas do segundo encontro do projeto Manifestações da ergatividade na Amazônia. QUEIXALÓS, F. (ed.). Brasília: Universidade de Brasília, 2003. 